\title{
Chlorogenic Acid Profiles and Antioxidant Potentials of 17 Sweet Potato Varieties Cultivated in Korea: Impact of Extraction Condition and Classification by Hierarchical Clustering Analysis
}

\author{
Ji Su Park ${ }^{1,2}$, Ja Won Woo ${ }^{1}$, Gyu-Hwan Choi ${ }^{3}$, Dong-Seong Choi ${ }^{1}$ and Mun Yhung Jung ${ }^{*}$ \\ ${ }^{1}$ College of Food Science, Woosuk University, Republic of Korea \\ ${ }^{2}$ Food Analysis Center, Korea Food Research Institute, Seongnam-Si, 463-746, Republic of Korea \\ ${ }^{3}$ Jeonbuk Agricultural Research and Extension Service, Iksan-Si, 570-704, Republic of Korea
}

'Correspondence to:

Mun Yhung Jung, $\mathrm{PhD}$

College of Food Science

Woosuk University, Samnye-eup

Wanju-gun, Jeonbuk Province 565-701

Republic of Korea

Tel: 82-63-290-1438

Fax: 82-63-291-9312

E-mail: munjung@woosuk.ac.kr

\section{Received: April 30, 2015}

Accepted: April 30, 2015

Published: June 26, 2015

Citation: Park JS, Woo JW, Choi GH, Choi DS, Jung MY. 2015. Chlorogenic Acid Profiles and Antioxidant Potentials of 17 Sweet Potato Varieties Cultivated in Korea: Impact of Extraction Condition and Classification by Hierarchical Clustering Analysis. J Food Chem Nanotechnol 1(1): 3-12.

Copyright: (C) 2015 Park et al. This is an Open Access article distributed under the terms of the Creative Commons Attribution 4.0 International License (CC-BY) (http://creativecommons. org/licenses/by/4.0/) which permits commercial use, including reproduction, adaptation, and distribution of the article provided the original author and source are credited.

Published by United Scientific Group

\begin{abstract}
A high resolution LC-ESI-QTOF-MS, LC-MS/MS, and HPLC-DAD analysis were conducted to isolate, identify and quantify the chlorogenic acids in 17 sweet potato varieties cultivated in Korea. The impacts of extracting solvent mixture system on the quantity and composition chlorogenic acids of the extracts were studied. It was found that extracting solvent mixture system greatly affected the quantity and quality of chlorogenic acids in the extracts of sweet potato. The optimum extracting solvent system was selected for extracting the chlorogenic acids from sweet potatoes. The profiles and quantities of chlorogenic acids in sweet potatoes were greatly different with variety, showing about 30 -fold variation in quantity. Juhwangmi contained the highest quantity of chlorogenic acid $(2393.65 \mu \mathrm{g} / \mathrm{g}$ dry weight), while Matnami contained the least quantity of chlorogenic acid $(68.62 \mu \mathrm{g} / \mathrm{g}$ dry weight). High correlations $(>0.97)$ were observed between chlorogenic acid contents and antioxidant potential data from DPPH, ABTS, FARP, and total phenolic assays. Sweet potatoes were statistically classified in 4 well defined groups in terms of their similarity in chlorogenic acid profile and quantity. This represents the first report on the profiles and quantity of chlorogenic acids as well as antioxidative potentials of several unreported sweet potato varieties.
\end{abstract}

\section{Keywords}

Chlorogenic acids, Sweet potato, LC-ESI-QTOF-MS/MS, Antioxidant potential, Hierarchical cluster analysis

\section{Introduction}

The sweet potato (Ipomoea batatas L.) is a dicotyledonous vegetable plant of the family convolvulaceae. It has been reported that sweet potato root contains high quantity of Chlorogenic acids [1,2]. Chlorogenic acids are a family of esters formed between caffeic acid and L-quinic acid. Most common chlorogenic acids found in sweet potatoes are 3-O-caffeoylquinic acid (3-CQA), 4-O-caffeoylquinic acid (4-CQA), 5-O-caffeoylquinic acid (5-CQA), 3,4-diO-caffeoylquinic acid (3,4-diCQA), 3,5-di-O-caffeoylquinic acid (3,5-diCQA), 4,5-di-O-dicaffeoylquinic acid (4,5-diCQA), and 3,4,5-tri-O-caffeoylquinic acid (3,4,5-triCQA) [2]. Sweet potatoes have been reported to have a range of beneficial functionalities due to high contents of chlorogenic acids. The chlorogenic acids extracted from sweet potato were found to inhibit the growth of human colon, leukemia, and stomach cancer cells, to ameliorate diabetes in humans, and to inhibit growth of viruses and fungi [3-6]. Caffeoyl quinic acids isolated from Japanese sweet potato leaves exhibited antimutagenic activities 
in the Ames Salmonella assay and selective inhibition of matrix metallo proteinase (MMP)-9, an angiogenic enzyme responsible for tumor invasion and metastasis [7].

Total phenolic acid contents in sweet potatoes (Ipomea batatas L.) as determined by $\mathrm{UV} / \mathrm{V}$ is spectrophotometric measurement after treatment with Folin-ciocalteu phenol reagent have been extensively reported [8-10]. It has been reported that there was great variation in total phenolic content with varieties $[1,8]$. However, there are surprisingly not so many reports on quantitative analytical data of the profiles and quantities of individual chlorogenic acids in various sweet potatoes [11-18]. Furthermore, there are various different varieties of sweet potatoes widely cultivated in Korea for edible and/or food processing purposes. Among them, the profiles and contents of chlorogenic acids in only 8 sweet potato roots have been previously reported [13]. The quantitative analysis of chlorogenic acids in the many other important sweet potato varieties in Korea has never been previously carried out. Therefore, an urgent need still exists to analyze total and individual chlorogenic acids in these sweet potatoes widely cultivated in Korea for the evaluation of their nutritional and health-promoting properties and commercial application values.

Thus, the objectives of this research were (1) to study the profile and quantity of individual and total chlorogenic acids in 17 different varieties of sweet potatoes cultivated widely in Korea by HPLC-DAD UV-Vis scanning spectra and high resolution LC-ESI-QTOF-MS ${ }^{2}$ analysis, (2) to measure the antioxidant potentials of the solvent extracts of the sweet potatoes by utilizing DPPH, ABTS, FARP, and Folin-ciocalteu phenol total phenolic assay, (3) to study the correlation between the quantities of chlorogenic acids and the data from the antioxidant potentials assays, and (4) to make a classification of the sweet potatoes by employing hierarchical cluster analysis (HCA) based on the data of the chlorogenic acid profiles and contents.

\section{Materials and Methods}

\section{Chemicals and materials}

5-Caffeoylquinic acid, 3,5-O-dicaffeoylquinic acid, formic acid, 2,2-diphenyl-1-picrylhydrazyl (DPPH), 2,2'-azobis-(2methylpropionamidine) dihydrochloride(AAPH), 2,2-azinobis(3-ethylbenzothiazoline-6-sulfonic acid) diammonium salt (ABTS), $\mathrm{FeCl}_{3}$, Folin-ciocalteu phenol reagent, and sodium ascorbate were purchased from Sigma-Aldrich (St.Louis, MO, USA). The HPLC-grade water and methanol were obtained from Fisher Scientific (Pittsburgh, PA, USA) and JT Baker Chemical (Co., Phillipsburg, NJ), respectively. Seventeen different varieties of sweet potatoes (Cheongsol, Goganmi, Hayarnmi, Helsimi, Jeungmi, Jinhongmi, Juhwangmi, Matnami, Shinchunmi, Shingeonmi, Shinhwangmi, Shinhyoung-3-ho, Shinyulmi, Su, Yeonhwangmi, Yeonmi and Yulmi) were obtained from Iksan-si Agricultural Technology Service Center (Iksan, Republic of Korea). All the sweet potatoes were grown in the cultivation fields under the same environment and cultivating conditions by Iksan-si Agricultural Technology Service Center in the year of 2010. The harvest season was October.
Impact of solvent system on the chlorogenic acids extraction from sweet potatoes

Sweet potatoes were first sliced into thin pieces, then freeze-dried and ground to make fine powder to pass through a $150 \mathrm{~mm}$ sieve. The impacts of solvent system on the chlorogenic acid contents and composition were studied by conducting the solvent extraction with a various extraction solvent mixture systems of ethanol or methanol. One hundred milligrams of the dried sweet potato powders were weighed, in duplicate, in a $15 \mathrm{~mL}$ capacity tube (SPL Life Sciences., Co., Ltd.). Then, $8 \mathrm{~mL}$ of extracting solvents was added to the sample tube. The sample tubes were caped, and placed in a water bath at $80^{\circ} \mathrm{C}$ for $10 \mathrm{~min}$. Then, the sample tubes were mixed briefly, and placed on a shaker (EYELA MMV$1000 \mathrm{~W}$, Tokyo, Japan) at a speed of $280 \mathrm{rpm}$ for $1 \mathrm{hr}$. Then, the samples were centrifuged at $2224.5 \mathrm{~g}$ for $20 \mathrm{~min}$ at $5^{\circ} \mathrm{C}$ with a refrigerated multi-purpose centrifuge (Combi-514R, Hanil Science, Seoul, Republic of Korea). The supernatant extract was transferred into a $15 \mathrm{~mL}$ tube and filtrated with a syringe filter.

\section{HPLC/DAD for separation and quantification of chlorogenic acids}

The HPLC-DAD analyses were performed on a HPLC equipped with a diode array detector (Agilent 1200 Series Diode array Detector, Agilent Technologies Inc., Santa Clara, CA, USA). The column used was a C18 HPLC column (Ascentis Express C18 column, $15 \mathrm{~cm} \mathrm{x} 4.6 \mathrm{~mm}, 2.7 \mathrm{~mm}$, Sigma-Aldrich Ltd.). The temperature programmable column oven (Agilent Technologies Inc.) was used to maintain the column temperature at $40^{\circ} \mathrm{C}$ during the HPLC analysis. The injection volume of the prepared sample was $10 \mu \mathrm{L}$. The mobile phase was a gradient prepared from $0.1 \%$ formic acid in water (component A) and methanol (component B). The gradient program for the HPLC was as following: 0-5min, $2-2 \% \mathrm{~B} ; 5-10 \mathrm{~min}, 2-10 \% \mathrm{~B} ; 10-50$ min $10-40 \% \mathrm{~B} ; 50-55$ $\min , 40-45 \% \mathrm{~B}$. The flow rate of mobile phase was $0.7 \mathrm{~mL}$ $\mathrm{min}^{-1}$. Quantifications of individual chlorogenic acids in sweet potatoes were obtained by HPLC-DAD at $326 \mathrm{~nm}$ using the standard calibration curves drawn based on authentic standards of 5-chlorogenic acid and 3,5-O-dicaffeoylquinic acid for the quantification of monocaffeoyl quinic acid (monoCQA) and dicaffeoyl quinic acid (di-CQA), respectively.

\section{LC-ESI-TOF-MS analysis for characterization}

HPLC-TOF-MS analysis were performed on the HPLC (UltiMate 3000 Series system, DIONEX Technologies, Sunnyvale, CA, USA) equipped with a diode array detector (DIONEX Technologies) and a QTOF/MS (quadrupoletime-of-flight mass spectrometer, micro QTOF-Q II, Bruker Daltonik, Bremen, Germany) in series in the same chromatographic line. The HPLC column and conditions for the mobile phase gradient were the same as those in HPLC/ $\mathrm{DAD}$ analysis. The HPLC column oven temperature was maintained at $40^{\circ} \mathrm{C}$. Mass spectra in the $\mathrm{m} / \mathrm{z}$ range $100-600$ were obtained by electrospray ionization with a negative-ion mode. The mass spectrometric conditions were optimized as follows: gas temperature $220^{\circ} \mathrm{C}$, drying gas flow rate 10.0 L min ${ }^{-1}$, nebulizer gas pressure $1.5 \mathrm{bar}$, and capillary and fragment or potentials $4,000 \mathrm{~V}$ and $220 \mathrm{~V}$, respectively. The mass axis was calibrated using the internal calibration solution 
(0.02 $\mathrm{N}$ lithium formatein 50\% propanol in water).

\section{LC-ESI-QTOF-MS/MS analysis for characterization}

The LC-QTOF-MS/MS analysis was performed with the same HPLC-MS spectrometer as described above. The mass spectrometric conditions for $\mathrm{MS}^{2}$ were identical to those for TOF/MS analysis. For obtaining MS/MS fragments ions, argon was used as a collision gas. The collision energy $(5 \mathrm{eV})$ was optimized for individual chlorogenic acid by performing the repeated analysis.

\section{DPPH assay}

Antioxidant potential against DPPH radicals was assayed according to a previous method, with some modifications [19, 20]. DPPH solution was prepared and $20 \mu \mathrm{L}$ of the sample were added. The reaction was taken for $30 \mathrm{~min}$ at $37^{\circ} \mathrm{C}$ in the dark and the absorbance was determined at $517 \mathrm{~nm}$ with a spectrophotometer (MECASYS Optizen pop, Daejeon, Korea). The external standard curve was drawn by using various concentrations of sodium ascorbate in $50 \% \mathrm{EtOH}$ solutions. DPPH radical scavenging activity was expressed as $\mu$ g sodium ascorbate equivalent $(\mathrm{AE}) / \mathrm{g}$ sample.

\section{ABTS assay}

The antioxidant potential against ABTS radical was assayed by the improved ABTS method [21, 22]. Briefly, the ABTS solution was prepared by the reaction of ABTS $(2.5 \mathrm{mM})$ by addition of AAPH and potassium phosphate buffer $(0.1 \mathrm{M})$, and placed at $68^{\circ} \mathrm{C}$ for $15 \mathrm{~min}$ in a water bath under the dark. The ABTS solution $(980 \mu \mathrm{L})$ was added to the sample extracts $(20 \mu \mathrm{L})$ and mixed thoroughly. The reaction mixture was incubated for $10 \mathrm{~min}$ at $37^{\circ} \mathrm{C}$ and the absorbance at $734 \mathrm{~nm}$ was determined with a spectrophotometer. An external standard curve was drawn using sodium ascrobate solution at various concentrations in 50\% ethanol. The absorbance of the reaction samples was compared to that of the sodium ascrobate standard curve. ABTS radical scavenging activity was expressed as $\mu \mathrm{g}$ sodium ascorbate equivalent (AE)/g sample.

\section{Ferric-ion reducing antioxidant power (FRAP) assay}

FRAP solution was prepared by mixing 10 portions of phosphate buffer ( $\mathrm{pH}$ 6.6) with one portion of $\mathrm{FeCl}_{3}$ solution. Addition of the sample was added to the FRAP solution and placed at $50^{\circ} \mathrm{C}$ for $20 \mathrm{~min}$. Then, the solution was centrifuged (10 min, $2224.5 \mathrm{~g}$ ) and absorbance was measured at a wavelength of $700 \mathrm{~nm}$ with a spectrophotometer [23, 24]. An external standard curve was obtained using sodium ascrobate solution at various concentrations in 50\% ethanol. The absorbance of the reaction samples was compared to that of the sodium ascrobate standard curve. FRAP antioxidative potential was expressed as $\mu \mathrm{g}$ sodium ascorbate equivalent (AE)/g sample.

Total phenolics with Folin-ciocalteu phenol regent method

Total phenolic contents of the extracts were determined by a previously reported colorimetric Folin-ciocalteu phenol regent assay [25] with a slight modification. Briefly, the filtered sample extract $(0.2 \mathrm{~mL})$ and distilled water $(1.8 \mathrm{~mL})$ were added to a $15 \mathrm{~mL}$ capacity tube. Then, $0.2 \mathrm{~mL}$ Folinciocalteu phenol reagent was added to this tube, and the tube was allowed to react at room temperature for $5 \mathrm{~min}$.
Two $\mathrm{mL}$ of $7 \%$ sodium carbonate aqueous solution and 0.8 $\mathrm{mL}$ distilled water were added to the tube, and mixed for 5 sec with a vortex. Then, the tube was set at room temperature for $90 \mathrm{~min}$. The absorbance was measured at $750 \mathrm{~nm}$ with a spectrophotometer. Chlorogenic acid (5-caffeoylquinicacid) was used as a standard for drawing a calibration curve. The total phenolic content was expressed as $\mu \mathrm{g}$ of Chlorogenic acid equivalent $(\mathrm{CAE}) / \mathrm{g}$ sample.

\section{Statistical analysis}

Duncan's multiple-range test was used to ascertain the differences in the obtained quantitative data at $\alpha=0.05$ by using a SPSS statistical analysis program (SPSS 14.0K, SPSS). The correlation between the data was obtained by the regression analysis using SigmaPlot 12.5 (Systat Software Inc., San Jose, CA, USA). The data of the chlorogenic acid profiles and quantity were analyzed for the classification of the sweet potatoes by employing multivariate statistical analysis using hierarchical cluster analysis (HCA). The similarities between the analyzed samples were presented in the dendrogram for each sweet potato variety. The dendrogram similarity scales that are generated by the SPSS statistical analysis program range from zero (greater similarity) to 25 (lower similarity).

\section{Results and Discussion}

\section{Separation and characterization of individual chlorogenic acid}

A HPLC chromatogram for the chlorogenic acids of a sweet potato variety is shown in (Figure 1). The peaks 1-6 of the HPLC chromatogram were identified by the combination of UV/Vis scanning spectra obtained by HPLC-DAD detector, high resolution LC-ESI-TOF/MS, and LC-ESI-QTOFMS/MS. The UV/Vis scanning spectra provided valuable information supporting the characterization of chlorogenic acids. Mass spectra in the $\mathrm{m} / \mathrm{z}$ range $100-600$ were acquired with a negative-ion mode LC-ESI-TOF/MS. LC-ESI-TOF/ MS has been known to offer the capability of unambiguous identification by simultaneously providing the information on exact mass measurements, fragment ion patterns, and isotope ion peaks. The TOF/MS also provides the full spectrum recorded at all times, which allows identification of nontarget compounds. Furthermore, the high resolution TOF/ MS analysis allowed the calculation of the molecular formulas with the obtained molecular ion data [26, 27]. The chemical formulas corresponding to the peaks 1-6 were first established after automatic calculation with the exact mass of the molecular ions $\left([\mathrm{M}-\mathrm{H}]^{-}\right)$obtained from the LC-TOF/MS analysis. Table 1 summarizes the identification of chlorogenic acids in sweet potatoes. In this study, excellent agreement was obtained between the theoretical and the actual experimental mass data of the peaks. The accuracy for confirmation of elemental compositions was less than \pm 6 ppm mass error, showing the high mass accuracy. Besides exact mass measurements, the abundances of the isotope peaks and fragment ions of the molecular ions $\left([\mathrm{M}-\mathrm{H}]^{-}\right)$were also monitored to confirm the identities of chemical formulas. Furthermore, LC-ESI-tandem MS analyses were carried out for the further confirmation of their structural identifications by using the data of the product ion patterns. The UV/Vis scanning spectra, LC-TOF-MS spectra and isotope pattern of [M]- ion, and LC-QTOF-MS ${ }^{2}$ 


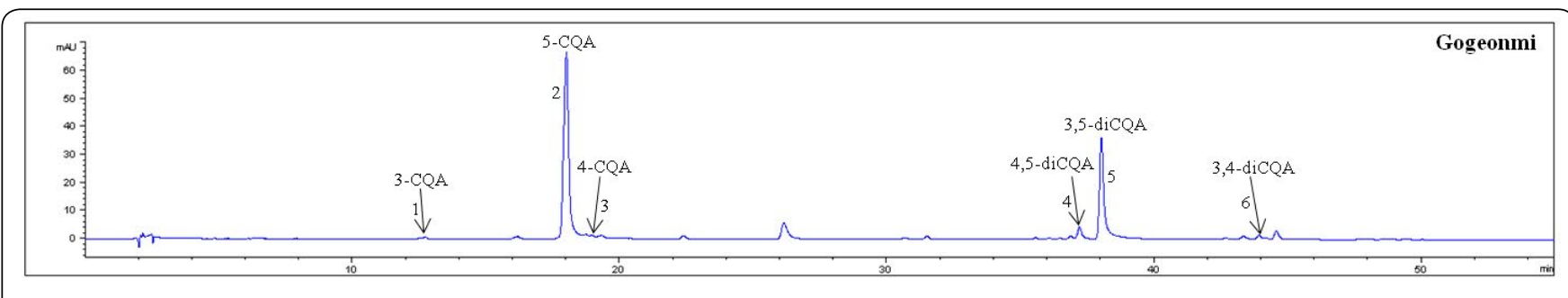

Figure 1: A representative HPLC-DAD chromatogram of chlorogenic acids in a sweet potato (Gogeonmi) cultivated in Korea.

Table 1: Identification of chlorogenic acid in sweet potato (Shinhwangmi) using HPLC-DAD and LC-ESI-QTOF-MS2.

\begin{tabular}{|c|c|c|c|c|c|c|c|c|c|}
\hline \multirow[b]{2}{*}{$\begin{array}{l}\text { Peak } \\
\text { No. }\end{array}$} & \multirow[b]{2}{*}{$\begin{array}{l}\text { R.T. } \\
(\min )\end{array}$} & \multirow[b]{2}{*}{ Formula } & \multicolumn{3}{|c|}{ TOF/MS } & \multirow{2}{*}{$\begin{array}{c}\text { Collision } \\
\text { Energy } \\
(\mathrm{eV}) \\
\end{array}$} & \multirow{2}{*}{$\begin{array}{c}\text { MS/MS } \\
\text { Fragment ions }(m / z)\end{array}$} & \multirow{2}{*}{$\begin{array}{c}\text { DAD } \\
\text { UV-VIS } \lambda_{\text {max }} \\
(\mathbf{n m})\end{array}$} & \multirow[b]{2}{*}{ Identification } \\
\hline & & & $\begin{array}{l}\text { Theoretical } \\
\operatorname{Mass}(m / z)\end{array}$ & $\begin{array}{c}\text { Experimental } \\
\text { Mass }(m / z)\end{array}$ & $\begin{array}{l}\text { Error } \\
(\mathrm{ppm})\end{array}$ & & & & \\
\hline 1. & 12.73 & $\mathrm{C}_{16} \mathrm{H}_{18} \mathrm{O}_{9}$ & 353.0867 & 353.0887 & 5.7 & 5 & $191.0560 / 353.0861$ & $326,299,242$ & 3-caffeoylquinic acid \\
\hline 2. & 19.01 & $\mathrm{C}_{16} \mathrm{H}_{18} \mathrm{O}_{9}$ & 353.0867 & 353.0876 & 2.5 & 5 & $191.0563 / 353.0862$ & $326,299,237$ & 5-caffeoylquinic acid \\
\hline 3. & 19.31 & $\mathrm{C}_{16} \mathrm{H}_{18} \mathrm{O}_{9}$ & 353.0867 & 353.0880 & 3.7 & 5 & $\begin{array}{l}191.0560 / 353.0945 / \\
173.0480 / 286.0767\end{array}$ & $324,296,234$ & 4-caffeoylquinic acid \\
\hline 4. & 37.21 & $\mathrm{C}_{25} \mathrm{H}_{24} \mathrm{O}_{12}$ & 515.1184 & 515.1186 & 0.4 & 5 & $\begin{array}{l}515.1184 / 384.9304 / \\
353.0885\end{array}$ & 326296240 & 4,5-dicaffeoylquinic acid \\
\hline 5. & 38.02 & $\mathrm{C}_{25} \mathrm{H}_{24} \mathrm{O}_{12}$ & 515.1184 & 515.1175 & -1.7 & 5 & $515.1184 / 353.0866$ & 326,298240 & 3,5-dicaffeoylquinic acid \\
\hline 6. & 43.92 & $\mathrm{C}_{25} \mathrm{H}_{24} \mathrm{O}_{12}$ & 515.1184 & 515.1153 & -6.0 & 5 & $\begin{array}{l}384.9304 / 515.1184 / \\
353.0875\end{array}$ & 326,298242 & 3,4-dicaffeoylquinic acid \\
\hline
\end{tabular}

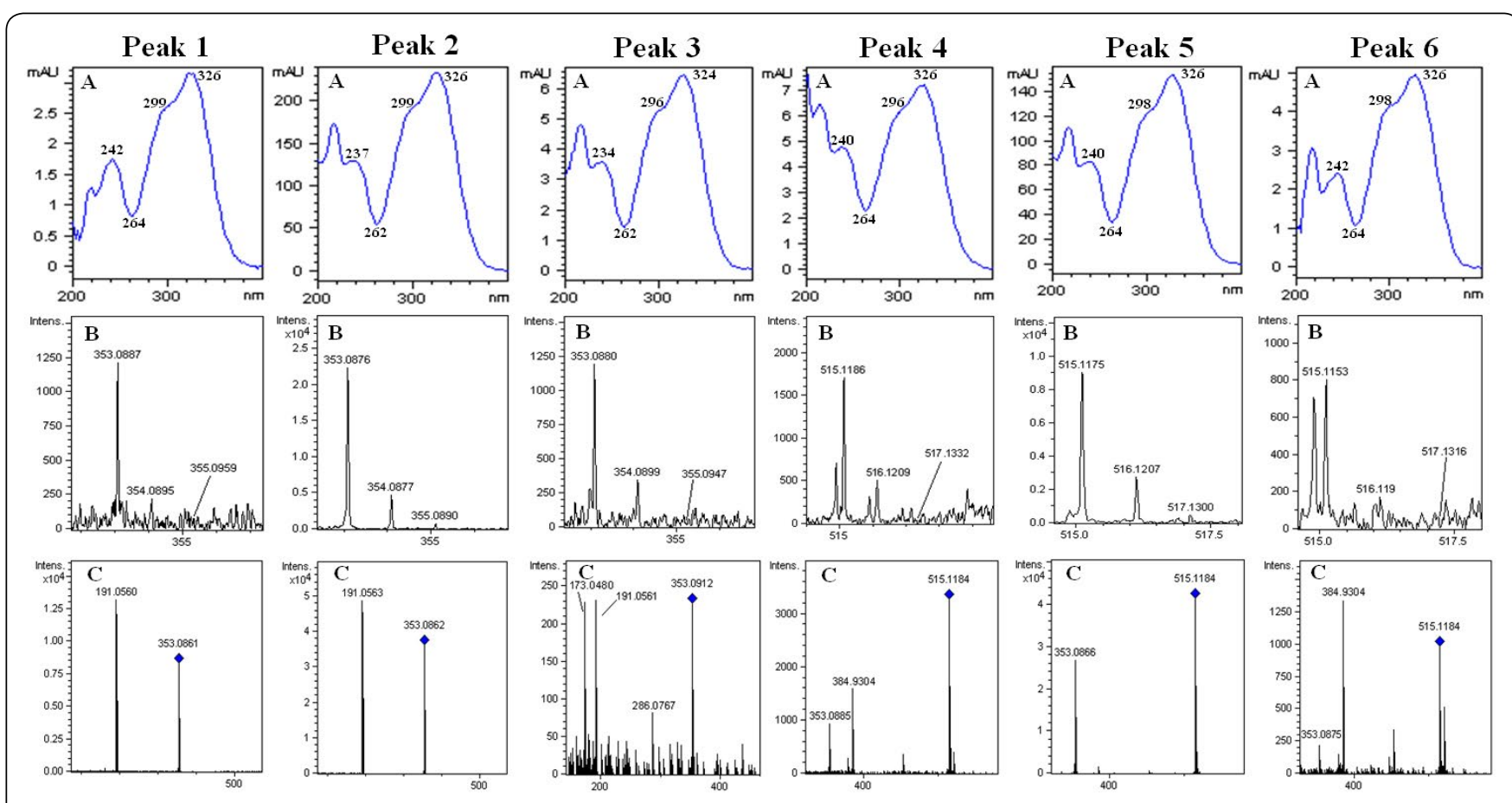

Figure 2: UV-Visible scanning spectra (A), LC-TOF/MS spectra (B), and LC-MS/MS spectra (C) for the HPLC peaks 1-6

product ion spectra of peaks 1-6 are shown in (Figure 2). The $\lambda_{\max }$ values the UV/VIS spectra of individual peaks isolated from a sweet potato extract were consistent with those of chlorogenic acids in the previous report [13]. As previously reported, the position and number of caffeoyl groups linked to quinic acid did not significantly affect the absorption spectra. The TOF/MS data showed that the peaks 1-3 had virtually the same molecular ion $(\mathrm{m} / z$ 353.0876-353.0887) (Table 1, Figure 2). With this exact mass data, the molecular formula of peaks 1-3 was calculated as $\mathrm{C}_{16} \mathrm{H}_{18} \mathrm{O}_{9}$. The experimental mass data of $\mathrm{m} / z$ 353.0876-353.0887 for peaks 1-3 were closely matched with the theoretical value 
$\left(\mathrm{m} / z\right.$ 353.0867) of $\mathrm{C}_{16} \mathrm{H}_{18} \mathrm{O}_{9}$ with the error of less than $2.5 \mathrm{ppm}$. Furthermore, the experimental isotope information (exact masses and pattern of isotopes) of [M-H]- ion was matched with those of its theoretical isotope information (exact masses and pattern of isotopes) within the tolerable error ranges (Table 1), confirming the correct assignment of their molecular formula. In the $\mathrm{MS}^{2}$ analysis, the molecular ion of peaks 1-3 was fragmented to a product ion, $\mathrm{m} / \mathrm{z} 191.0560$ ([M-caffeic acid $\left.]^{-}\right)$, due to the loss of caffeic acid from their structures (Figure 2). The results clearly showed that the peaks 1-3 were monoester of caffeoyl quinic acid with the molecular formula of $\mathrm{C}_{16} \mathrm{H}_{18} \mathrm{O}_{9}$. The identity of monoester of caffeoyl quinic acid of peaks 1-3 were assigned by the previously reported eluting order of these compounds. Thus, peaks 1 , 2 , and 3 were tentatively assigned as 3-CQA, 5-CQA, and 4-CQA, respectively. The $\mathrm{MS}^{2}$ spectra of peak 3 (Table 1 , Figure 2) showed the characteristic product ion $\mathrm{m} / z 173.0480$ along with $\mathrm{m} / z$ 191.0561, which was a unique product ion for 4-CQA, confirming the identity of peak 3. Furthermore, the identity of peak 2 was confirmed by comparing its retention time with that of authentic 5-CQA.

The LC-TOF/MS data showed that the peaks 4-6 had virtually the same molecular ion $(\mathrm{m} / \mathrm{z}$ 515.1153-515.1186) (Table 1 and Figure 2). The molecular formula $\mathrm{C}_{25} \mathrm{H}_{24} \mathrm{O}_{12}$ of the peaks 4-6 was calculated from this exact mass data. The experimental mass value of $(\mathrm{m} / z$ 515.1153-515.1186) for peaks 4-6 was closely matched with the theoretical value $(\mathrm{m} / z 515.1183)$ of $\mathrm{C}_{25} \mathrm{H}_{24} \mathrm{O}_{12}$ with the error of less than 6.0 ppm. LC-QTOF-MS ${ }^{2}$ showed that the product ions of peaks 4-6 obtained from their parent ion $(\mathrm{m} / \mathrm{z} 515.1184)$ were $\mathrm{m} / \mathrm{z}$ 353.0886 and 191.0550, due to the losses of one and two caffeic acids from their structures, respectively. The results showed unambiguously that the structural identification of peaks 4-6 were dicaffeoyl quinic acids. The identities of individual compounds of peaks 4-6 were tentatively assigned as 3,4-diCQA, 3,5-diCQA, and 4,5-diCQA, respectively, based on the previously reported eluting order of these compounds.
The identity of peak 5 was further confirmed by comparing its retention time with that of authentic 3,5-diCQA. Unlike most of the previous reports [12], none of the tested sweet potatoes contained tricaffeoyl quinic acid (3,4,5-triCQA) in this study. We tried to check meticulously the presence 3,4,5-triCQA by LC-TOF/MS with a selective ion mode. But we failed to found the presence of tricaffeoyl quinic acid in the sweet potatoes. This result was consistent with another previous report on the Korean sweet potato varieties [13].

\section{Impact of extracting solvents on chlorogenic acid extraction}

For studying the impact of different solvent on the contents and composition of chlorogenic acids extracted from sweet potato, six different extracting solvent systems, which have been frequently used for extracting chlorogenic acids, were tested. The tested extraction solvents were 50\%, 80\%, and $100 \%$ methanol or $50 \%, 80 \%$, and $100 \%$ ethanol. The extraction efficiency and profiles of chlorogenic acids from sweet potatoes were greatly dependent on the extracting solvent type (Table 2). It was found that pure ethanol (100\%) were not efficient solvents for extracting chlorogenic acids from sweet potatoes. Pure methanol was much better in chlorogenic acid extraction than pure ethanol $(\mathrm{p}<0.05)$. The chologenic acid extraction by $100 \%$ methanol was about 2.4 times higher than that by $100 \%$ ethanol. The results showed that mono- and dicaffeoyl quinic acids are more soluble to the higher polarity solvent (methanol) than lower polarity solvent of ethanol. Monocaffeoyl quinic acid is more polar than dicaffeoyl quinic acid. The solubility dependent extraction efficiency was further proven by the addition of water to the ethanol, which created more polar environment in the extracting solvent system. It was found that the addition of water to ethanol dramatically increased the extraction efficiency from 655.55 to $1978.36 \mu \mathrm{g}$ chlorogenic acid/g, which represented about 3 fold increase in chlorogenic acid extraction by adding $50 \%$ water to ethanol. However, the addition of $50 \%$ water to methanol drastically decreased the chlorogenic acid extraction from 1578.79 to $930.97 \mu \mathrm{g}$ chlorogenic acid/g. Furthermore, it is

\begin{tabular}{|c|c|c|c|c|c|c|c|c|c|c|}
\hline \multirow[b]{2}{*}{$\begin{array}{l}\text { Sweet } \\
\text { potato } \\
\text { Varieties }\end{array}$} & \multicolumn{10}{|c|}{ Chlorogenic Acids ( $\mu \mathrm{g} / 1 \mathrm{~g}$ sweet potato powder) ${ }^{\text {a) }}$} \\
\hline & 3-CQA & 5-CQA & 4-CQA & 4,5-diCQA & 3,5-diCQA & 3,4-diCQA & Mono CQA & Di CQA & Total & $\begin{array}{l}\text { Ratio of } \\
\text { Mono- } \\
\text { CQA/ } \\
\text { Di- } \\
\text { CQA }\end{array}$ \\
\hline $\begin{array}{l}50 \% \\
\text { Ethanol }\end{array}$ & $19.94 \pm 1.49^{a}$ & $1133.60 \pm 8.21^{\mathrm{a}}$ & $15.68 \pm 1.05^{\mathrm{a}}$ & $24.47 \pm 0.28^{c}$ & $770.37 \pm 1.40^{\mathrm{b}}$ & $14.29 \pm 0.91^{\mathrm{c}}$ & $1169.22 \pm 10.75^{\mathrm{a}}$ & $809.13 \pm 2.60^{\mathrm{a}}$ & $1978.36 \pm 13.35^{\mathrm{a}}$ & 1.44 \\
\hline $\begin{array}{l}80 \% \\
\text { Ethanol }\end{array}$ & $14.44 \pm 0.42^{\mathrm{b}}$ & $678.26 \pm 6.18^{\mathrm{d}}$ & $14.64 \pm 0.14^{\mathrm{ab}}$ & $22.48 \pm 0.28^{\mathrm{d}}$ & $571.76 \pm 2.67^{\mathrm{d}}$ & $11.27 \pm 0.28^{\mathrm{d}}$ & $707.35 \pm 5.61^{\mathrm{d}}$ & $605.51 \pm 2.67^{c}$ & $1312.86 \pm 8.28^{\mathrm{d}}$ & 1.16 \\
\hline $\begin{array}{l}100 \% \\
\text { Ethanol }\end{array}$ & $6.67 \pm 0.05^{\mathrm{c}}$ & $238.46 \pm 3.37^{\mathrm{f}}$ & $4.81 \pm 0.14^{\mathrm{d}}$ & $35.93 \pm 0.35^{\mathrm{a}}$ & $363.72 \pm 4.91^{\mathrm{e}}$ & $5.96 \pm 0.21^{\mathrm{f}}$ & $249.94 \pm 3.56^{\mathrm{f}}$ & $405.61 \pm 5.47^{\mathrm{d}}$ & $655.55 \pm 9.03^{\mathrm{f}}$ & 0.61 \\
\hline $\begin{array}{l}80 \% \\
\text { Methanol }\end{array}$ & $18.86 \pm 0.35^{\mathrm{a}}$ & $946.70 \pm 1.6^{\mathrm{b}}$ & $14.64 \pm 0.42^{\mathrm{ab}}$ & $26.60 \pm 0.91^{\mathrm{b}}$ & $751.22 \pm 1.97^{c}$ & $17.47 \pm 0.21^{\mathrm{b}}$ & $980.20 \pm 2.39^{b}$ & $795.29 \pm 0.84^{\mathrm{b}}$ & $1775.49 \pm 1.54^{\mathrm{b}}$ & 1.23 \\
\hline $\begin{array}{l}100 \% \\
\text { Methanol }\end{array}$ & $14.79 \pm 0.35^{\mathrm{b}}$ & $706.20 \pm 6.95^{\mathrm{c}}$ & $13.80 \pm 0.63^{b}$ & $36.03 \pm 0.21^{\mathrm{a}}$ & $784.02 \pm 6.95^{\mathrm{a}}$ & $19.95 \pm 0.35^{\mathrm{a}}$ & $734.79 \pm 7.23^{c}$ & $840.00 \pm 6.39^{\mathrm{a}}$ & $1584.79 \pm 0.84^{c}$ & 0.87 \\
\hline
\end{tabular}


Table 3: Chlorogenic acid compositions and contents of different sweet potato varieties determined by the high performance liquid chromatography-diode array detector.

\begin{tabular}{|c|c|c|c|c|c|c|c|c|c|c|}
\hline \multirow[b]{2}{*}{$\begin{array}{l}\text { Sweet potato } \\
\text { Varieties }\end{array}$} & \multicolumn{10}{|c|}{ Contents of Chlorogenic Acids $(\mu \mathrm{g} / 1 \mathrm{~g} \text { sweet potato powder })^{1,2)}$} \\
\hline & 3-CQA & 5-CQA & 4-CQA & 4,5-diCQA & 3,5-diCQA & 3,4-diCQA & Mono-CQA & Di-CQA & Total & $\begin{array}{l}\text { Ratio of } \\
\text { Mono- } \\
\text { CQA/ } \\
\mathrm{Di}^{-} \\
\text {CQA }\end{array}$ \\
\hline Cheongsol & $14.31 \pm 0.95^{\mathrm{d}}$ & $772.01 \pm 2.25^{\mathrm{d}}$ & $12.27 \pm 2.02^{\mathrm{f}}$ & $13.02 \pm 0.73^{\mathrm{fg}}$ & $402.66 \pm 33.86^{\mathrm{de}}$ & $7.15 \pm 0.28^{\mathrm{fg}}$ & $798.59 \pm 3.32^{c}$ & $798.59 \pm 3.32^{c}$ & $1221.42 \pm 31.55^{\mathrm{d}}$ & 1.88 \\
\hline Goganmi & $9.65 \pm 0.11^{\mathrm{g}}$ & $683.12 \pm 4.66^{\mathrm{e}}$ & $11.26 \pm 0.72^{\mathrm{f}}$ & $10.68 \pm 0.22^{g}$ & $326.04 \pm 1.97^{\mathrm{ef}}$ & $13.98 \pm 2.08^{\mathrm{d}}$ & $704.02 \pm 5.27^{d}$ & $704.02 \pm 5.27^{\mathrm{d}}$ & $1054.71 \pm 9.54^{\mathrm{e}}$ & 2.00 \\
\hline Hayarnmi & $19.94 \pm 1.49^{\mathrm{a}}$ & $1133.60 \pm 8.21^{\mathrm{a}}$ & $15.68 \pm 1.05^{\mathrm{f}}$ & $24.47 \pm 0.28^{\mathrm{fg}}$ & $770.37 \pm 1.40^{\mathrm{b}}$ & $14.29 \pm 0.91^{\mathrm{d}}$ & $1371.65 \pm 5.09^{a}$ & $1371.65 \pm 5.09^{\mathrm{a}}$ & $1978.36 \pm 13.35^{b}$ & 1.55 \\
\hline Helsimi & $6.71 \pm 0.34$ & $277.12 \pm 1.97 \mathrm{j}$ & $26.48 \pm 0.11^{\mathrm{b}}$ & $14.69 \pm 3.76 \mathrm{e}^{\mathrm{f}}$ & $220.71 \pm 0.90^{\mathrm{gh}}$ & $8.93 \pm 0.34^{\mathrm{e}}$ & $310.08 \pm 2.19^{i}$ & $310.08 \pm 2.19^{\mathrm{i}}$ & $554.41 \pm 7.19^{g}$ & 1.26 \\
\hline Jeungmi & $8.10 \pm 0.06^{\mathrm{hi}}$ & $159.44 \pm 0.84^{1}$ & $12.78 \pm 0.28^{\text {ef }}$ & $13.10 \pm 0.39^{\mathrm{fg}}$ & $157.50 \pm 1.35^{\mathrm{h}}$ & $8.46 \pm 0.34^{\mathrm{ef}}$ & $180.33 \pm 0.51^{\mathrm{k}}$ & $180.33 \pm 0.51^{\mathrm{k}}$ & $359.39 \pm 1.91^{\mathrm{h}}$ & 1.00 \\
\hline Jinhongmi & $17.55 \pm 0.17^{\mathrm{b}}$ & $348.27 \pm 0.95^{\mathrm{i}}$ & $7.78 \pm 0.39^{g}$ & $27.00 \pm 0.39^{\mathrm{b}}$ & $390.47 \pm 0.45^{\mathrm{de}}$ & $14.65 \pm 0.34^{\mathrm{d}}$ & $373.60 \pm 1.52^{\mathrm{h}}$ & $373.60 \pm 1.52^{\mathrm{h}}$ & $805.72 \pm 1.12^{\mathrm{f}}$ & 0.86 \\
\hline Matnami & $3.02 \pm 0.28^{\mathrm{k}}$ & $25.17 \pm 0.39^{\mathrm{m}}$ & $\mathrm{n} \cdot \mathrm{a}^{\mathrm{h}}$ & $4.80 \pm 0.11^{\mathrm{h}}$ & $40.62 \pm 0.00^{\mathrm{i}}$ & n. $\mathrm{a}^{\mathrm{i}}$ & $28.19 \pm 0.11^{1}$ & $28.19 \pm 0.11^{1}$ & $73.61 \pm 0.22^{\mathrm{i}}$ & 0.62 \\
\hline Shinchunmi & $8.58 \pm 0.06^{\mathrm{h}}$ & $155.51 \pm 0.56^{1}$ & $9.29 \pm 0.17^{g}$ & $40.06 \pm 1.01^{\mathrm{a}}$ & $280.85 \pm 0.73^{\text {fg }}$ & $9.73 \pm 0.00^{\mathrm{e}}$ & $173.38 \pm 0.79^{k}$ & $173.38 \pm 0.79^{k}$ & $504.02 \pm 2.53^{\mathrm{g}}$ & 0.52 \\
\hline Shingeonmi & $10.73 \pm 0.16^{\mathrm{f}}$ & $434.66 \pm 18.58^{\mathrm{g}}$ & $12.86 \pm 0.28^{\text {ef }}$ & $39.03 \pm 2.02^{\mathrm{a}}$ & $237.26 \pm 15.33^{\mathrm{gh}}$ & $4.49 \pm 0.22^{\mathrm{h}}$ & $458.25 \pm 18.46^{\mathrm{f}}$ & $458.25 \pm 18.46^{\mathrm{f}}$ & $739.03 \pm 35.59^{f}$ & 1.63 \\
\hline Shinhwangmi & $25.37 \pm 0.00^{\mathrm{a}}$ & $1041.79 \pm 26.67^{\mathrm{c}}$ & $50.34 \pm 2.30^{\mathrm{a}}$ & $21.44 \pm 0.28^{\mathrm{cd}}$ & $1217.23 \pm 129.70^{a}$ & $37.48 \pm 1.74^{a}$ & $1117.50 \pm 28.97^{b}$ & $1117.50 \pm 28.97^{\mathrm{b}}$ & $2393.65 \pm 13.00^{\mathrm{a}}$ & 0.87 \\
\hline $\begin{array}{l}\text { Shinhyoung } \\
\text {-3-ho }\end{array}$ & $7.35 \pm 0.00^{\mathrm{i}}$ & $407.66 \pm 6.23^{\mathrm{h}}$ & $8.46 \pm 0.11^{g}$ & $24.74 \pm 0.34^{\mathrm{bc}}$ & $354.54 \pm 4.44^{\text {ef }}$ & $6.11 \pm 0.06^{\mathrm{g}}$ & $423.47 \pm 6.12^{g}$ & $423.47 \pm 6.12^{\mathrm{g}}$ & $808.86 \pm 10.84^{f}$ & 1.09 \\
\hline Shinyulmi & $12.55 \pm 0.06^{\mathrm{e}}$ & $242.54 \pm 0.84^{k}$ & $15.52 \pm 0.56^{\mathrm{d}}$ & $21.88 \pm 0.45^{\mathrm{cd}}$ & $200.14 \pm 1.01^{\mathrm{gh}}$ & $8.70 \pm 0.45^{\text {ef }}$ & $270.02 \pm 1.35^{g}$ & $270.02 \pm 1.35^{g}$ & $500.73 \pm 3.26^{\mathrm{g}}$ & 1.17 \\
\hline $\mathrm{Su}$ & $25.13 \pm 0.22^{\mathrm{a}}$ & $631.58 \pm 4.44^{f}$ & $14.29 \pm 0.84^{\mathrm{de}}$ & $18.18 \pm 0.17^{\mathrm{de}}$ & $605.74 \pm 3.93^{c}$ & $19.61 \pm 0.39^{c}$ & $671.01 \pm 5.05^{\mathrm{e}}$ & $671.01 \pm 5.05^{\mathrm{e}}$ & $1314.54 \pm 9.21^{\mathrm{d}}$ & 1.04 \\
\hline Yeonhwangmi & $3.73 \pm 0.06^{\mathrm{k}}$ & $30.90 \pm 0.66^{\mathrm{m}}$ & $\mathrm{n} \cdot \mathrm{a}^{\mathrm{h}}$ & $3.81 \pm 0.28^{\mathrm{h}}$ & $30.17 \pm 0.06^{\mathrm{i}}$ & $\mathrm{n} \cdot \mathrm{a}^{\mathrm{i}}$ & $34.63 \pm 0.61^{1}$ & $34.63 \pm 0.61^{1}$ & $68.62 \pm 0.83^{\mathrm{i}}$ & 1.01 \\
\hline Yeonmi & $3.69 \pm 0.00^{\mathrm{k}}$ & $38.19 \pm 3.09^{\mathrm{m}}$ & $\mathrm{n} \cdot \mathrm{a}^{\mathrm{h}}$ & $3.77 \pm 0.00^{\mathrm{h}}$ & $74.20 \pm 0.11^{\mathrm{i}}$ & $\mathrm{n} \cdot \mathrm{a}^{\mathrm{i}}$ & $41.89 \pm 3.09^{1}$ & $41.89 \pm 3.09^{1}$ & $119.86 \pm 2.98^{\mathrm{i}}$ & 0.53 \\
\hline
\end{tabular}

${ }^{1)}$ The data with different superscript letter within same column are statistically different at $\alpha=0.05$.

2) One hundred milligrams of the dried sweet potato powders were extracted with $8 \mathrm{ml}$ of extracting solvent ( $50 \%$ ethanol).

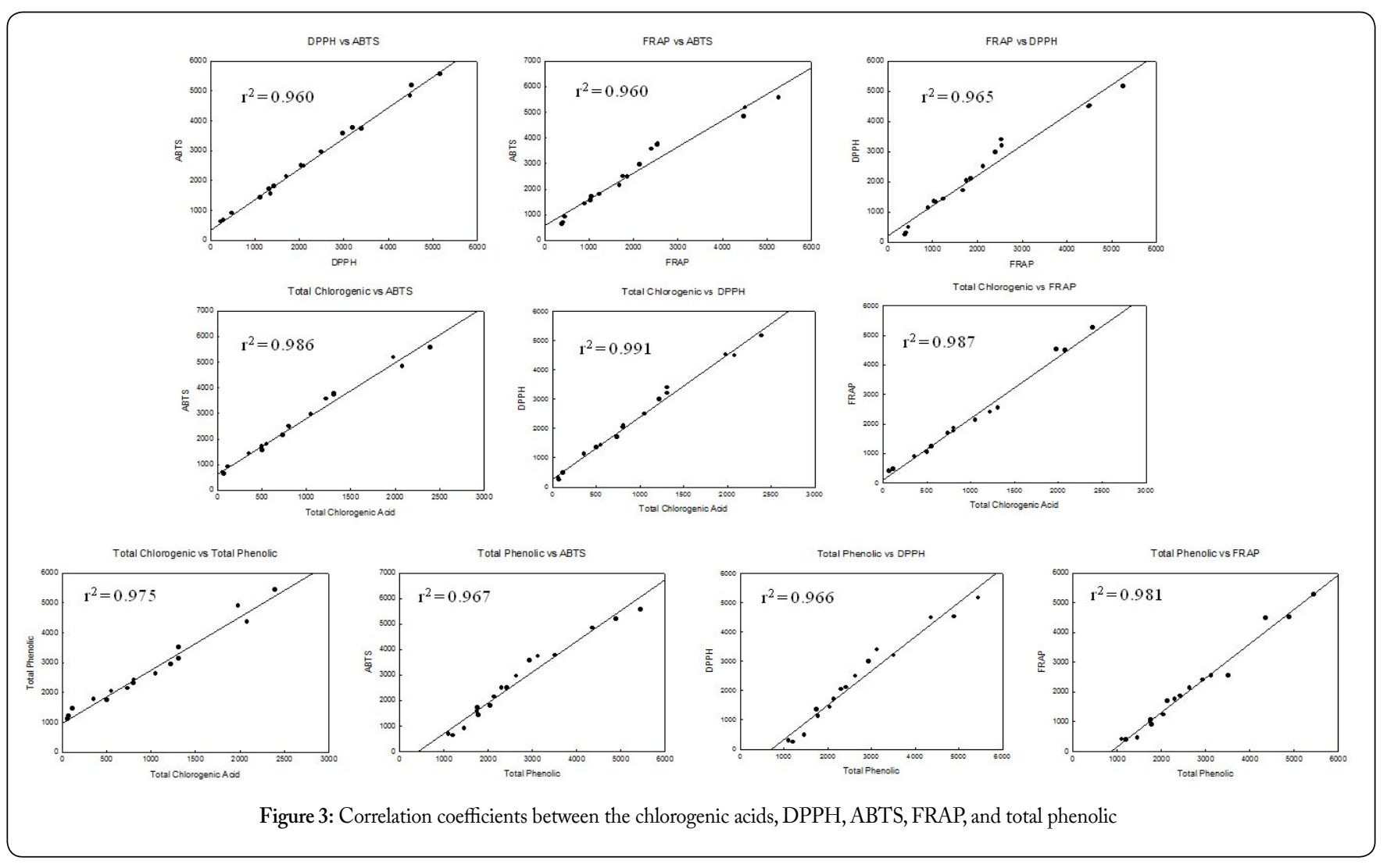


interesting to note that the ratio of monocaffeoyl quinic acid to dicaffeoyl quinic acid was also greatly influenced by the types of extracting solvent, indicating the selective extracting power with the different types of solvents. For example, the ratio of monocaffeoyl quinic acid to dicaffeoyl quinic acid was 0.61 in $100 \%$ ethanol extract, while that was 2.56 in the $50 \%$ methanol extract, indicating the great differences in selective extraction power with different solvent system. The different selectivity for the extracting solvents may be due to the solubility difference of individual chlorogenic acids toward the different solvents. In this experiment, the $50 \%$ aqueous ethanol showed the highest extraction of chlorogenic acids $(1978.36 \mu \mathrm{g} / 1 \mathrm{~g} \mathrm{dw})$, whereas $100 \%$ ethanol provided the least quantity of chlorogenic acid extraction $(655.55 \mu \mathrm{g} / 1 \mathrm{~g})$. It is also interesting to note that the contents of total chlorogenic acids as well as mono-caffeoyl quinic acids and di-caffeoyl quinic acids were highest in the extract obtained by $50 \%$ ethanol solvent. Thus, the $50 \%$ aqueous ethanol was selected as an extracting solvent for the quantification of chlorogenic acids from sweet potatoes. Previously, three commonly used solvents (80\% acetone, $80 \%$ methanol, and 80\% ethanol) were compared for chlorogenic acid extraction efficiency in sweet potato [14]. The authors reported that $80 \%$ acetone showed the significantly lower extraction efficiency than $80 \%$ methanol and $80 \%$ ethanol for the extraction of chlorogenic acids from sweet potato [14]. The extraction efficiency of $80 \%$ methanol was not significantly different to that of $80 \%$ ethanol. In our present study, however, it was found that $80 \%$ methanol showed significantly higher extraction efficiency than $80 \%$ ethanol (Table 2). Furthermore, in the previous report, the authors did not study the extraction efficiency of $50 \%$ and $100 \%$ methanol and ethanol systems. In our study, it was clearly found that $50 \%$ ethanol showed significantly higher extraction efficiency for the chlorogenic acids from sweet potato than $80 \%$ methanol (Table 2).

\section{Quantifications of chlorogenic acids in sweet potatoes}

Quantifications of chlorogenic acids in sweet potatoes were obtained by HPLC-DAD at $326 \mathrm{~nm}$ using the standard calibration curve with authentic standards of 5-CQA and 3,5-diCQA for the measurements of monocaffeoyl quinic acids and dicaffeoyl quinic acids, respectively. Table 3 shows the distribution of total and individual chlorogenic acids in various sweet potatoes. The chlorogenic acid contents in the sweet potatoes varied greatly with varieties, ranging from 68.62 $\mu \mathrm{g} / \mathrm{g}$ to $2393.65 \mu \mathrm{g} / \mathrm{g}$ dry weight (dw), which represented about 30 -fold variation with varieties as determined by the HPLC analysis. Shinhwangmi showed the highest quantity of chlorogenic acid $(2393.65 \mu \mathrm{g} / \mathrm{g} \mathrm{dw})$, followed by Juhwangmi (2080.16 $\mu \mathrm{g} / \mathrm{gdw})$, and Hayarnmi (1978.36 $\mu \mathrm{g} /$ $\mathrm{gdw}$ ) in a decreasing order. Yeonhwangmi contained the least quantity of chlorogenic acids $(68.62 \mu \mathrm{g} / \mathrm{gdw})$. Our result was in agreement with the previous report in that Shinhwangmi contained the high contents of chlorogenic acids [13]. However, the authors reported the contents of chlorogenic acids in only 8 selected Korean sweet potato varieties. In this present report, chlorogenic acid contents in 17 different Korean sweet potato varieties were analyzed. In our present study, it was newly found that Juhwangmi and Hayarnmi were also the rich sources for chlorogenic acids, along with the previously reported Shinghwangmi. The chlorogenic acid contents in sweet potatoes in Korea were within the range of previously reported values in other sweet potato varieties. The previously reported chlorogenic acid contents in various sweet potato genotypes were in the range of $40-13936 \mu \mathrm{g} / \mathrm{g}$ sample $\mathrm{dw}[12,14-18]$. The chlorogenic acid contents in 8 selected Korean sweet potato varieties have been reported previously, ranging in 240.40-2386 $\mu \mathrm{g} / \mathrm{g}$ fresh weight (fw) [13]. It has been reported that the total quantities of chlorogenic acids in Shinhwangmi, Biomi, and Shingeonmi were 2386,866 and $1182 \mu \mathrm{g} / \mathrm{g}$ fw, respectively. The chlorogenic acid profiles and contents in many Korean sweet potatoes varieties have never been previously reported. It was found that 5-CQA and 3,5-diCQA were the most prevalent chlorogenic acids in all the sweet potatoes varieties in Korea. This result was consistent with previous reports for the sweet potato varieties from Europe, US, and Korea [13, 14]. The chlorogenic acid contents in the sweet potatoes were somewhat lower than the reported values of chorogenic acids in coffees, the most wellknown rich source of chlorogenic acids. The reported contents of total chlorogenic acids in coffees were in the range of 5260 $-17100 \mu \mathrm{g} / \mathrm{g}$ [28].

\section{Antioxidative potentials of sweet potatoes}

Reactive oxygen species (ROS) have been postulated to induce chronic diseases including cancer and arteriosclerosis through oxidative damage of biological components including DNA, proteins, and lipids. Antioxidants such as phenolic compounds have been known to remove or scavenge ROS to protect the biological components from the oxidative stress. Antioxidant potentials of the sweet potatoes were determined by DPPH (2,2-diphenyl-1-picrylhydrazyl), ABTS (2,2'-azinobis (3-ethylbenzothiazoline 6-sulfonate)), FRAP (ferric reducing antioxidant potential), and Folin-Ciocalteu reagent total phenolic assays Table 4. The antioxidant potentials of DPPH, ABTS, and FRAP assays were expressed as $\mu \mathrm{g}$ sodium ascorbate equivalent $(\mathrm{AE}) / \mathrm{g}$ sweet potato. The total phenolic contents by Folin-ciocalteu phenol reagent was expressed as $\mu \mathrm{g}$ chlorogenic acid equivalent (CAE)/g sample. Table 4 showed the antioxidant potentials of sweet potatoes as determined by DPPH, ABTS, FRAP, and total phenolics assays. There were also significant variations on the antioxidant potentials of the sweet potatoes depending on their varieties (Table 4). The antioxidant potentials of DPPH, ABTS, FRAP, and total phenolics for the sweet potatoes were in the range of 242.20-5167.51 $\mu \mathrm{g} \mathrm{AE} / \mathrm{g}, 629.91-5559.26$ $\mu \mathrm{g} \mathrm{AE} / \mathrm{g}, 392.38-5262.39 \mu \mathrm{g} \mathrm{AE} / \mathrm{g}$, and 1106.34-5443.02 $\mu \mathrm{g}$ CAE/g, respectively. Shinhwangmi showed the highest antioxidant potential, and Matnami the least antioxidant potential. Shinhwangmi exhibited the highest DPPH radical scavenging activity. ABTS activity was quantified in terms of percentage inhibition of the ABTS radical cation by antioxidants in each sample. Again Shinhwangmi exhibited the highest ABTS radical scavenging activity. Shinhwangmi displayed the highest FRAP values (5262.37 AE $\mu \mathrm{g} / \mathrm{g} \mathrm{dw}$ ) followed by Hayarnmi (4515.84 AE $\mu \mathrm{g} / \mathrm{g} \mathrm{dw}$ ) (Table 4). Total phenolic assay by Folin-Ciocalteu reagent actually measures a sample's reducing capacity, but this is not reflected in the name "total phenolic assay" [29, 30]. Previous study showed that many nonphenolic compounds do indeed show considerable 
Table 4: Antioxidant activities in lyophilized sweet potatoes as determined by DPPH, ABTS, FRAP, total phenolics with Folin-ciocalteu phenol reagent.

\begin{tabular}{|c|c|c|c|c|}
\hline \multirow{2}{*}{$\begin{array}{l}\text { Sweet potato } \\
\text { Varieties }\end{array}$} & \multicolumn{4}{|c|}{ Antioxidant activity ${ }^{1,2)}$} \\
\hline & $\begin{array}{l}\text { DPPH } \\
(\mu \mathrm{g} A E / g)^{3)}\end{array}$ & $\begin{array}{l}\text { ABTS } \\
(\mu \mathrm{g} \mathrm{AE} / \mathrm{g})\end{array}$ & $\begin{array}{l}\text { FRAP } \\
(\mu \mathrm{g} \mathrm{AE} / \mathrm{g})\end{array}$ & $\begin{array}{l}\text { Total Phenolic } \\
(\mu \mathrm{g} \mathrm{CAE} / \mathrm{g})^{4)}\end{array}$ \\
\hline Cheongsol & $2985.53 \pm 28.41^{\mathrm{e}}$ & $3566.60 \pm 26.09^{\mathrm{e}}$ & $2403.61 \pm 31.05^{\mathrm{d}}$ & $2935.85 \pm 10.45^{\mathrm{f}}$ \\
\hline Gogeonmi & $2496.62 \pm 115.23^{\mathrm{f}}$ & $2957.73 \pm 52.18^{\mathrm{f}}$ & $2135.74 \pm 49.68^{\mathrm{e}}$ & $2632.82 \pm 0.00^{\mathrm{g}}$ \\
\hline Hayarnmi & $4524.68 \pm 64.02^{\mathrm{b}}$ & $5181.02 \pm 26.09^{\mathrm{b}}$ & $4515.84 \pm 37.26^{\mathrm{b}}$ & $4896.08 \pm 20.90^{\mathrm{b}}$ \\
\hline Helsimi & $1428.26 \pm 38.41^{\mathrm{i}}$ & $1799.95 \pm 71.75^{\mathrm{i}}$ & $1239.91 \pm 12.42^{\mathrm{i}}$ & $2045.54 \pm 50.17^{\mathrm{k}}$ \\
\hline Jeungmi & $1129.48 \pm 25.60^{j}$ & $1430.94 \pm 71.75^{1}$ & $901.78 \pm 31.05^{\mathrm{k}}$ & $1778.99 \pm 5.97^{1}$ \\
\hline Jinhongmi & $2043.92 \pm 38.41^{\mathrm{g}}$ & $2496.46 \pm 26.09 \mathrm{~g}$ & $1762.47 \pm 18.63^{\mathrm{g}}$ & $2307.29 \pm 33.45^{\mathrm{i}}$ \\
\hline Juhwangmi & $4488.47 \pm 89.62^{\mathrm{b}}$ & $4835.07 \pm 58.70^{c}$ & $4485.10 \pm 18.63^{\mathrm{b}}$ & $4363.93 \pm 20.90^{c}$ \\
\hline Matnami & $242.20 \pm 76.82^{1}$ & $629.91 \pm 71.75^{\mathrm{n}}$ & $392.38 \pm 31.05^{\mathrm{m}}$ & $1203.90 \pm 29.27^{\mathrm{n}}$ \\
\hline Shinchunmi & $1355.83 \pm 12.80^{\mathrm{i}}$ & $1564.70 \pm 39.13^{\mathrm{k}}$ & $1033.51 \pm 18.63^{j}$ & $1749.42 \pm 11.95^{1}$ \\
\hline Shingeonmi & $1708.93 \pm 0.00^{\mathrm{h}}$ & $2145.90 \pm 39.13^{\mathrm{h}}$ & $1687.82 \pm 49.68^{\mathrm{h}}$ & $2135.82 \pm 8.36^{\mathrm{j}}$ \\
\hline Shinhwangmi & $5167.51 \pm 25.60^{\mathrm{a}}$ & $5559.26 \pm 13.04^{\mathrm{a}}$ & $5262.37 \pm 24.84^{\mathrm{a}}$ & $5443.02 \pm 0.00^{\mathrm{a}}$ \\
\hline Shinhyoung -3-ho & $2107.30 \pm 25.60^{\mathrm{g}}$ & $2482.62 \pm 6.52^{\mathrm{g}}$ & $1863.48 \pm 24.84^{\mathrm{f}}$ & $2425.54 \pm 50.17^{\mathrm{h}}$ \\
\hline Shinyulmi & $1328.67 \pm 25.60^{\mathrm{i}}$ & $1707.70 \pm 19.56^{\mathrm{j}}$ & $1064.25 \pm 37.26^{j}$ & $1762.09 \pm 29.86^{1}$ \\
\hline $\mathrm{Su}$ & $3193.76 \pm 25.60^{\mathrm{d}}$ & $3764.94 \pm 19.56^{\mathrm{d}}$ & $2548.52 \pm 12.42^{\mathrm{c}}$ & $3512.34 \pm 52.26^{\mathrm{d}}$ \\
\hline Yeonhwangmi & $296.53 \pm 76.82^{1}$ & $692.91 \pm 6.52^{\mathrm{n}}$ & $414.33 \pm 24.84^{1 \mathrm{~m}}$ & $1106.34 \pm 16.72^{\circ}$ \\
\hline Yeonmi & $486.66 \pm 89.62^{\mathrm{k}}$ & $909.71 \pm 52.18^{\mathrm{m}}$ & $467.03 \pm 62.10^{1}$ & $1461.11 \pm 0.00^{\mathrm{m}}$ \\
\hline Yulmi & $3393.90 \pm 12.80^{c}$ & $3732.65 \pm 13.04^{\mathrm{d}}$ & $2539.74 \pm 12.42^{c}$ & $3128.01 \pm 10.45^{\mathrm{e}}$ \\
\hline
\end{tabular}

1) The data with different superscript letter within same column are the statistically different at $\alpha=0.05$

2) One hundred milligrams of the dried sweet potato powders were extracted with $8 \mathrm{ml}$ of extracting solvent (50\% ethanol).

${ }^{3)} \mu \mathrm{g} \mathrm{AE} / \mathrm{g}=\mu \mathrm{g}$ Sodium Ascorbate Equivalent/g sample

${ }^{4)} \mu \mathrm{g}$ CAE $/ \mathrm{g}=\mu \mathrm{g}$ Chlorogenic Acid Equivalent/g sample

reactivity toward the $\mathrm{F}-\mathrm{C}$ reagent [30]. Total phenolic content of the sweet potatoes was in the range of $1106.34 \mu \mathrm{g}-5443.02$ $\mu \mathrm{g} \mathrm{CAE} / \mathrm{g}$ dw (Table 4). Folin-ciocalteu phenol reagent total phenolic content was also greatly dependent on the sweet potato variety. Shinhwangmi, hawanmi, and Juhwangmi contained high total phenolic contents (5443.02, 4896.08, and $4363.93 \mu \mathrm{g} \mathrm{CAE} / \mathrm{g} \mathrm{dw}$, respectively), whereas Matnami, Yeonmi, Yeonhwangmi contained very low quantity of total phenolics (1203.90, 1461.11, and $1106.34 \mu \mathrm{g} \mathrm{CAE} / \mathrm{g} \mathrm{dw}$, respectively). Taken all together, Shinhwangmi, hawanmi, and Juhwangmi showed highest antioxidative potentials, indicating the rich sources for the antioxidative compounds.

Correlation between total chlorogenic acids and antioxidative potential assays

A regression analysis was performed to correlate the obtained data with the different assays. The highest correlations were found between DPPH and ABTS assays $\left(r^{2}=0.996\right)$ (Figure 3). The correlations between the total cholorogenic acid as determined by HPLC and the data obtained from antioxidative potential assays were also studied. Strong correlations $\left(r^{2}>0.97\right)$ were found between the chlorogenic acid contents and assays for the antioxidant potentials (DPPH, ABTS, FRAP, total phenolics). The correlations between chlorogenic acid contents and antioxidative potentials were DPPH $\left(r^{2}=0.97\right)$, ABTS $\left(r^{2}=0.98\right)$, FRAP $\left(r^{2}=0.98\right)$, and total phenolics $\left(r^{2}=0.97\right)$ (Figure 3). These results indicated a strong relationship between chlorogenic acid concentration in sweet potatoes and their radical scavenging and reducing capacity. The results suggested that chlorogenic acids in sweet potatoes contribute significantly to their antioxidant potential. The types of chlorogenic acids with different number of phenolic $-\mathrm{OH}$ would also affect the antioxidative activity. Nevertheless, we found that some sweet potato varieties possessed strong antioxidant activities were associated with high total chlorogenic acid content. Among the 17 selected sweet potatoes analyzed, Shinhwangmi, Juhwangmi, and Hayarnmi were found to be the important potential sources of natural antioxidants, among Korean sweet potatoes. Previously, only Shinghwangmi has been reported to be an important antioxidant potential source [13]. In the present study, however, two additional sweet potato varieties have been found to possess high antioxidant potential along with significantly high contents of chlorogenic acids.

\section{Classification by hierarchical cluster analysis}

Considerable variations were observed between the sweet potatoes in terms of profiles and quantities of chlorogenic acids. In hierarchical cluster analysis, sweet potatoes are grouped on the basis of similarities, without taking into account the information about the class membership. Multivariate statistical analysis using hierarchical cluster analysis (HCA) was performed to identify the similarity groups between the different types of sweet potatoes based on the profiles and quantity of chlorogenic acids. HCA rendered dendrogram, in which four well-defined clusters were visible, grouping the 
types of sweet potatoes into four major statistically significant clusters (Figure 4). A group of samples (Cluster A) is clearly discernible which is composed of Shinhwangmi, Juhwangmi, and Hayarnmi. These sweet potato varieties are associated with high content of chlorogenic acids, ranging from 1978.36 to $2393.65 \mu \mathrm{g} / \mathrm{g}$. A second cluster (Cluster B) consists of $\mathrm{Su}$, Goganmi, Yulmi and Cheongsol containing the medium high level of chlorogenic acids, ranging from 1221.24 to $1314.54 \mu \mathrm{g} / \mathrm{g}$ (Table 3). A third cluster (Cluster C) includes Shigunmi, Shinhyoung-3-ho, Jinhongmi, Shinchunmi, Jeungmi, Shinyulmi and Helsimi, containing medium low level of chlorogenic acids, ranging from 554.41 to $808.36 \mu \mathrm{g} / \mathrm{g}$. Cluster D consists of Yeonmi, Yeonhwangmi, and Matnami, containing very low quantity of chlorogenic acids ranged from 68.62 to $119.86 \mu \mathrm{g} / \mathrm{g}$. It was quite useful technique for statistical classification of sweet potatoes based on the chlorogenic acid profiles and contents. Clusters A-D were well separated due to variations in profiles and quantity of chlorogenic acids in sweet potatoes. The HCA statistical analysis clearly showed that the dissimilarity between the Cluster A (Shinhwangmi, Juhwangmi, and Hayarnmi) and the other Clusters (B, C, D) were very high $(>18)$ (Figure 4$)$, indicating significantly

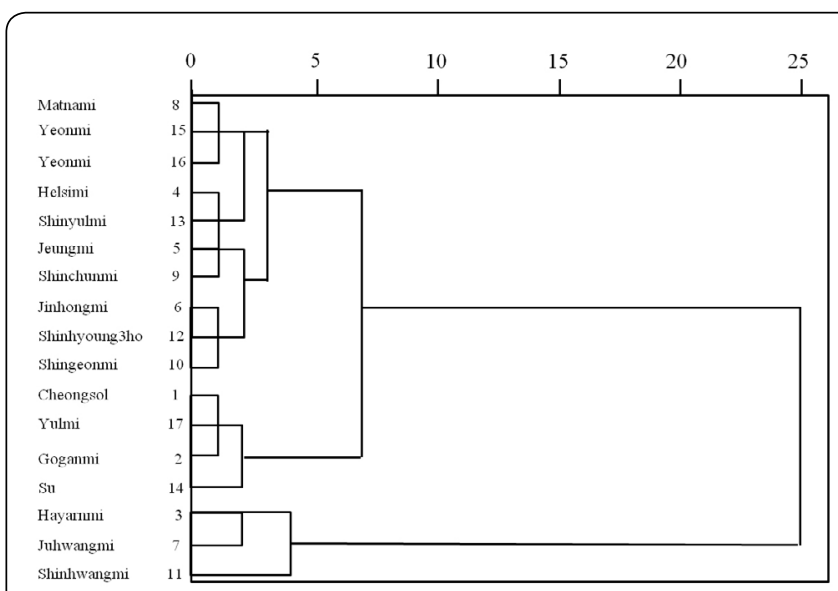

Figure 4: Dendrogram of 17 Korean varieties of sweet potatoes based on the profiles and quantity of chlorogenic acids obtained by HPLC-DAD analysis

different classification of Cluster A from the other clusters in terms of chlorogenic acid profiles and quantities. Since there is no clear genetic information on these sweet potato varieties, the relationship between Cluster groups and genetic similarity cannot be discussed. Nevertheless, the classification of Cluster group was clearly correlated with the chlorogenic acid quanity.

\section{Conclusion}

Chlorogenic acids in 17 sweet potato varieties in Korea were identified and quantified by high resolution LC-ESIQ-TOF-MS/MS and HPLC-DAD analysis. Six different chlorogenic acids (3-caffeoylquinic acid, 5-caffeoylquinic acid, 4-caffeoylquinic acid, 4,5-di-O-caffeoylquinic acid, 3,5-di-Ocaffeoylquinic acid, and 3,4-di-O-caffeoylquinic acid) were identified in the sweet potatoes. The profiles and quantity of chlorogenic acid in sweet potatoes differed greatly with variety. There was about 30 -fold variation in total chlorogenic acid content with varieties as determined by the HPLC analysis. Folin-Ciocalteu reagent total phenolic contents,
DPPH and ABTS radical scavenging activities, and ferric ion reducing antioxidant power (FARP) of sweet potatoes were also determined to study their antioxidative potentials. High correlations (>0.96) were observed between chlorogenic acid quantity and the antioxidative potential data of DPPH,ABTS, FARP, and total phenolics. Hierarchical cluster analysis (HCA) was performed to identify the similarity groups between the different types of sweet potatoes based on the chlorogenic acids and antioxidant activities. Samples were grouped in 4 well defined cluster groups in terms of their nearness or similarity in chlorogenic acid contents and antioxidant activities. This represents the first report on the profiles and quantity of chlorogenic acids as well as antioxidative potentials of unreported Korean sweet potato varieties.

\section{References}

1. Ishiguro K, Yahara S, Yoshimoto M. 2007. Changes in polyphenols content and radical-scavenging activity of sweet potato (Ipomoea batatas L.) during storage at optimal and low temperatures.J Agric Food Chem 55(26): 10773-10778. doi: 10.1021/jf072256v

2. Zheng W, Clifford MN. 2008. Profiling the chlorogenic acids of sweet potato (Ipomoea batatas) from China. Food Chem 106(1): 147-152. doi: 10.1016/j.foodchem.2007.05.053

3. Kurata R, Adachi M, Yamakawa O, Yoshimoto M. 2007. Growth suppression of human cancer cells by polyphenolics from sweet potato (Ipomoea batatas L.) leaves. J Agric Food Chem 55(1): 185-190. doi: 10.1021/jf0620259

4. Ludvik B, Hanefeld M, Pacini M. 2008. Improved metabolic control by Ipomoea batatas (Caiapo) is associated with increased adiponectin and decreased fibrinogen levels in type 2 diabetic subjects. Diabetes Obes Metab 10(7): 586-592. doi: 10.1111/j.1463-1326.2007.00752.x

5. Mahmood N, Moore PS, De-Tommasi N, De-Simone F, Colman S, et al. 1993. Inhibition of HIV infection by caffeoylquinic acid derivatives. Antivir Chem Chemoth 4(4): 235-240. doi: 10.1177/095632029300400406

6. Peterson JK, Harrison HF, Snook ME, Jackson DM. 2005. Chlorogenic acid content in sweet potato germplasm: possible role in disease and pest resistance. Allelopathy J 16(2): 239-249.

7. Yoshimoto M, Yahara S, Okuno S, Islam MS, Ishiguro K, et al. 2002. Antimutagenicity of mono-, di-, and tricaffeoyl quinic acid derivatives isolated from sweet potato (Ipomoea batatas L.) leaf. Biosci Biotech Bioch 66(11): 2336-2341. doi: 10.1271/bbb.66.2336

8. Teow CC, Truong VD, McFeeters RF, Thompson RL, Pecota KV, et al. 2007. Antioxidant activities, phenolic and b-carotene contents of sweet potato genotypes with varying flesh colours. Food Chem 103(3): 829838. doi:10.1016/j.foodchem.2006.09.033

9. Oki T, Masuda M, Furuta S, Nishiba Y, Terahara N, et al. 2002. Involvement of anthocyanins and other phenolic compounds in radicalscavenging activity of purple-fleshed sweet potato cultivars. J Food Sci 67(5): 1752-1756. doi: 10.1111/j.1365-2621.2002.tb08718.x

10. Rabah IO, Hou DX, Komine SI, Fujii M. 2004. Potential chemo preventive properties of extract from baked sweet potato (Ipomoea batatas Lam. Cv. Koganesengan). J Agric Food Chem 52(23): 7152-7157. doi: $10.1021 / \mathrm{jf0} 049368 \mathrm{w}$

11. Harrison Jr HF, Mitchell TR, Peterson JK, Wechter P, Majetich GF, et al. 2008. Contents of caffeoylquinic acid compounds in the storage roots of sixteen sweet potato genotypes and their potential biological activity. J Am Soc Hortic Sci 133(4): 492-500.

12. Islam MS, Yoshimoto M, Yakara S, Okuno S, Ishiguro K, et al. 2002. Identification and Characterization of Foliar Polyphenolic Composition in Sweetpotato (Ipomoea batatas L.) Genotypes. J Agric Food Chem 50(13): 3718-3722. doi: 10.1021/jf0201201

13. Jung JK, Lee SU, Kozukue N, Levin CE, Friedman M. 2011. Distribution of phenolic compounds and antioxidative activities in 
parts of sweet potato (Ipomoea batatas L.) plants and in home processed roots. J Food Compos Anal 24(1): 29-37. doi: 10.1016/j.jfca.2010.03.025.

14. Padda MS, Picha DH. 2008. Quantification of phenolic acids and antioxidant activity in sweet potato genotypes. Sci Horic-Amsterdam 119(1): 17-20. doi: 10.1016/j.scienta.2008.07.008

15. Sasaki K, Han J, Shimozono H, Villareal MO, Isoda H. 2013. Caffeoylquinic acid-rich purple sweet potato extract, with or without anthocyanin, imparts neuro protection and contributes to the improvement of spatial learning and memory of SAMP8 mouse.J Agric Food Chem 61(21): 5037-5045. doi: 10.1021/jf3041484

16. Son KC, Severson RF, Snook EM, Kays SJ. 1991. Root carbohydrate, organic acids, and phenolic chemistry in relation to sweet potato weevil resistance. Hortscience 26(10): 1305-1308.

17. Truong VD, Mc Feeters RF, Thompson RT, Dean LL, Shofran B. 2007. Phenolic acid content and composition in leaves and roots of common commercial sweet potato (Ipomea batatas L.) cultivars in the United States. J Food Sci 72(6): 343-349. doi: 10.1111/j.17503841.2007.00415.x

18. Zhu F, Cai YZ, Yang X, Ke J, Corke H. 2010. Anthocyanins, hydroxycinnamic acid derivatives, and antioxidant activity in roots of different Chinese purple-fleshed sweet potato genotypes. J Agric Food Chem 58(13): 7588-7596. doi: 10.1021/jf101867t

19. Blois MS. 1958. Antioxidant determinations by the use of a stable free radical. Nature 181(4617): 1199-1200. doi:10.1038/1811199a0

20. Okawa M, Kinjo J, Nohara T, Ono M. 2001. DPPH (1,1-diphenyl-2picrylhydrazyl) radical scavenging activity of flavonoids obtained from some medicinal plants. Biol Pharm Bull 24(10): 1202-1205. doi: 10.1248/bpb.24.1202

21. Halvorsen BL, Holte K, Myhrstad MCW, Barikmo I, Hvattum E, et al. 2002. A systematic screening of total antioxidants in dietary plants. JNutr 132(3): 461-471.
22. Vinson JA, Hao Y, Su X, Zubik L. 1998. Phenol antioxidant quantity and quality in foods: vegetables. J Agric Food Chem 46(9): 3630-3634. doi: $10.1021 /$ jf980295o

23. Benzie IFF, Szeto YT. 1999. Total antioxidant capacity of teas by the ferric reducing/antioxidant power assay. J Agric Food Chem 47(2): 633636. doi: 10.1021/jf9807768

24. Pulido R, Bravo L, Saura-Calixto F. 2000. Antioxidant activity of dietary polyphenols as determined by a modified ferric reducing/ antioxidant power assay. J Agric Food Chem 48(8): 3396-3402. doi: $10.1021 /$ jf9913458

25. Singleton VL, Orthofer R, Lamuela-Raventos RM. 1999. Analysis of total phenol and other oxidation substrates and antioxidants by means of Folin-Ciocalteu reagent. Method Enzymol 299: 152-178. doi: 10.1016/S0076-6879(99)99017-1

26. Park JS, Jung MY. 2012. Development of high-performance liquid chromatography-time-of-flight mass spectrometry for the simultaneous characterization and quantitative analysis of gingerolrelated compounds in ginger products. J Agric Food Chem 60(40): 10015-10026. doi: 10.1021/jf302944p

27. Lee MJ, Park JS, Choi DS, Jung MY. 2013. Characterization and quantitation of anthocyanins in purple-fleshed sweet potatoes cultivated in Korea by HPLC-DAD and HPLC-ESI-QTOF-MS/MS. J Agric Food Chem 61(12): 3143-3158. doi: 10.1021/jf3055455

28. Fujioka K, Shibamoto T. 2008. Chlorogenic acid and caffeine contents in various commercial brewed coffees. Food Chem 106: 217-221. doi: 10.1016/j.foodchem.2007.05.091

29. Huang D, Ou B, Prior RL. 2005. The chemistry behind antioxidant capacity assays. J Agric Food Chem 53(6): 1841-1856. doi: 10.1021/ jf030723c

30. Everrtte JD, Bryant QM, Green AM, Abbey YA, Wanglia GW, et al. 2010. Thorough study of reactivity of various compound classes toward the Folin-Ciocalteu reagent. J Agric Food Chem 58(14): 8139-8144. doi: 10.1021/jf1005935 